\title{
The effect of part sequence on succession threshold ${ }^{1,2}$
}

\author{
JOSEPH H. MCFARLAND ${ }^{3}$ \\ ANTIOCH COLLEGE
}

When letters of the word POT and the nonsense syllable OTP are presented in a typical orientation (horizontal) and $a$ typical order (left to right, up to down), succession threshold is lower relative to presentation in an atypical orientation (vertical) and an atypical order (right to left, down to up). These results are interpreted as showing that learning to read English establishes both orientation and order parameters of a hypothetical analysis operation.

In studying visual form perception, it is customary to present a form with its parts simultaneous. It is not clear, however, whether the investigator selects this method because he assumes that the visual system simultaneously processes stimulation arising from a form's parts, or because he assumes that typically a form's parts simultaneously stimulate the retina, or both. It is also customary to select perception of a spatial property as a dependent variable. Here, it is not clear whether the investigator chooses this variable because he assumes that the visual system processes stimulation from a form in regard to spatial properties only, or because he assumes that typically a form provides a spatial stimulus to the retina, or both. While it is not clear which assumptions are made in many studies of visual form perception, it is evident that some of these assumptions are frequently made by the investigator. $^{4}$

Prompted by speculations of Lashley $(1942,1951)$, a series of studies has been conducted that is based on an alternative set of assumptions. The visual system is assumed to be a spatial-temporal system that operates in two ways upon stimulation arising from a form. It analyzes, producing a sequence of spatially distributed responses to the line and angle parts of retinal stimulation arising from a form; and it integrates, producing one response to the sequence of part responses (McFarland, 1965a, b, 1967). ${ }^{5}$

In terms of these assumptions, everyday perception of a form's parts as simultaneous in time and joined in space is an achievement of the operations of analysis and integration. In other words, while a visual form's parts may be simultaneous and joined in terms of retinal stimulation, perception of the parts as simultaneous and joined depends on hypothetical neural network that produces a sequence of responses to parts in different first-order cortical neurones, and that then produces a response to this sequence of responses in a second-order cortical neurone. Such a view of visual form perception does not seem too far-fetched in light of Hubel and Wiesel's (1959) now-classic findings in the cat and the recent start at extending these findings to neural units in the human visual cortex (Marget al, 1968).

In some of these studies, the method of stimulus presentation consists in presenting sequentially the parts of a visual form and measuring perceived temporal properties of the form's parts. Interpart interval (IPI) is varied and $S$ s report whether the form's parts appear simultaneously or successively. The IPI at which the simultaneous response drops to $50 \%$ is taken as a succession threshold-an index of integration.

Using this method, a number of parameters relevant to the analysis operation have been found to affect the succession threshold. Succession threshold varies as a function of whether line $(27 \mathrm{msec})$ or angle $(20 \mathrm{msec})$ parts of a triangle are presented in sequence. Succession threshold also varies as a function of whether the line parts of a triangle are presented in a clockwise (15 msec) or counterclockwise (20 msec) sequence, and as a function of whether the letters of the word POT are presented in a left-right ( $14 \mathrm{msec})$ or a right-left $(17 \mathrm{msec})$ sequence. Insofar as succession threshold differs for these conditions, these data suggest that perception of a form's parts as simultaneous, viz., integration, requires different amounts of time depending on type of part and type of sequence composing the analysis operation.

The study reported here deals with the effect of letter sequence on the succession threshold. It has been proposed that the left-right sequence of presenting the letters POT results in a lower integration time due to the coincidence between this order and the typical order of analysis, viz., left-right, which is specified by learning to read (McFarland, 1965b). Bryden's recent report that letters on the left of a display and instructions to recall in a left-right order facilitate short-term memory provides sore support for this in terpretation (Bryden et al, 1968; Dick \& Mewhort, 1967).

The design of the study is based on a number of considerations. First, it is assumed that English words are read in two orjentations: typically horizontal and atypically vertical. Second, it is assumed that left to right is the typical order of reading when the word is horizontal and up to down is the typical order of reading when the word is vertical. If spatial order of reading specifies the typical order of the analysis operation, then presenting parts of a lecter form in a sequence that coincides with this order can be expected to lower integration time, viz., lead to a lower succession threshold.

\section{Method and Procedure}

Integration time is indexed by means of a succession threshold for eight volunteer college students. A threshold is determined for the word POT under conditions of presenting the word both in typical and atypical orientation in combination with typical and atypical orders of letter presentation. A 4 by 4 Latin square is used to arrange these four conditions with two Ss in each sequence. A method of limits is used to determine a threshold with five trials presented in a block at each IPI on ascending and descending series. An equal number of $S s$ in each of the four Latin square sequences are tested in an ascending-descending and a descending-ascending order.

For control purposes, the letters forming the word POT are spatially rearranged to form the nonsense syllable OTP and presented to a second group of eight Ss under the same four conditions. Both groups are tested on 3 consecutive days.

On each trial, the letters ( 1 deg of visual angle in height) are flashed for $10 \mathrm{msec}$ each in a particular sequence at a particular interpart interval (IPI). IPIs are maintained equal and varied over blocks of five trials from 0 to $40 \mathrm{msec}$ in 10 -msec steps on an ascending series of trials; the order is reversed on a descending series of trials. The succession threshold, viz., the IPI at which the response of simultaneous drops to $50 \%$, is added to the duration of the parts and taken as the index of time required for integration.

Subjects are instructed to report whether the letters are simultaneous or successive; they are also instructed to disregard any brightness differences. The criteria provided for the Ss are: "Letters are simultaneous when all letters both come on and go off together; letters are successive when one or more either comes on or goes off before the other(s)." 


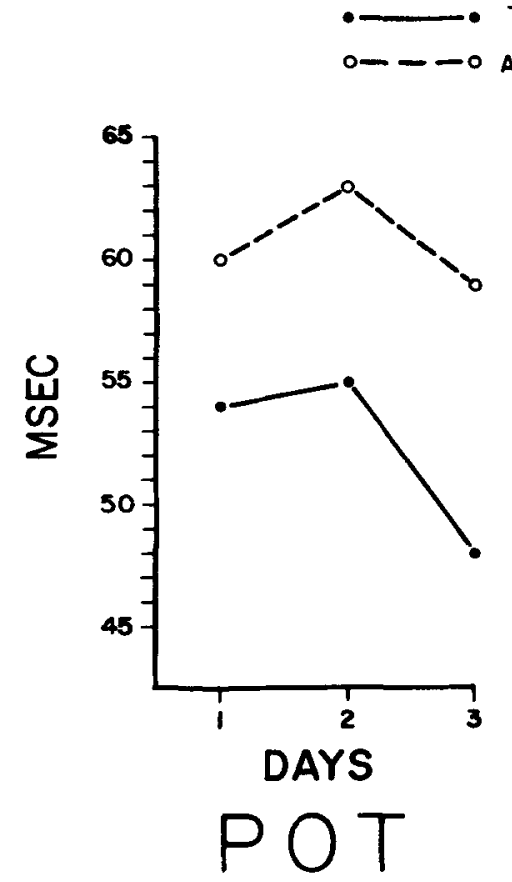

Subjects are dark adapted for $10 \mathrm{~min}$. The luminous letters, $.4 \mathrm{ft}-\mathrm{L}$, are rear-projected on a Pola-coat screen straight ahead at eye level. Letters are formed by transilluminating $35-\mathrm{mm}$ negatives in separate projectors by Sylvania R1131C tubes. Control of pulse duration, interpulse duration, and sequence of pulses is accomplished by Iconix equipment

All Ss and the research assistant testing the Ss are unfamiliar with the experimental question and are also unfamiliar with each other.

\section{Results}

All Ss correctly identify the letters on all trials and report the letters to be "clearly" visible. The psychophysical functions for the two response categories are comparable to those in other studies (McFarland, 1965a, 1967).

The integration time for both the word POT and the nonsense syllable OTP is smaller over the 3 test days $(F=40.39$, $\mathrm{p}<.005$, $\mathrm{df}=1 / 15$ ) for typical order of letter presentation (left-right and up-down) than for atypical order (Fig. 1). The integration time for both letter forms is smaller over the 3 test days $(F=11.32$, $\mathrm{p}<.005, \mathrm{df}=1 / 15)$ for typical orientation (horizontal) than for atypical orientation (Fig. 2). Further, when these forms are in a typical orientation and the letters are

Fig. 2. Mean integration time for typical and atypical orientation of word form as a function of test days for the POT and OTP groups of Ss.
Fig. 1. Mean integration time for typical and atypical order of letter presentation as a function of test days for the POT aind OTP groups of Ss.

of this study support the interpretation offered for the results of previous studies. Perception of a letter form's parts as simultaneous requires different amounts of time (integration of the sequence of responses to letter parts requires different amounts of time), depending on the type of sequence of responses to letters. The results also support the interpretation that a lower integration time for a left-right sequence is due to a coincidence between this order and the typical order of analysis that is specified by learning to read in a left-right order. Results show that when letters of the word POT and the nonsense syllable OTP are presented in a typical (horizontal) orientation, succession threshold is lower than when they are presented in a vertical (atypical) orientation. When these letters are presented in a typical order (left-right and up-down), the succession threshold is lower than when the letters are presented in an atypical order (right-left and down-up). Furthermore, the succession threshold is lowest when the letters are presented in a typical orientation and typical order, and the succession threshold is highest when they are presented in an atypical orientation and atypical order.

The design of this study was based on the assumptions that reading of English is typically horizontal and left to right. The

Insofar as integration time is affected by sequence of letter presentation, the results
AL ORIENTATION
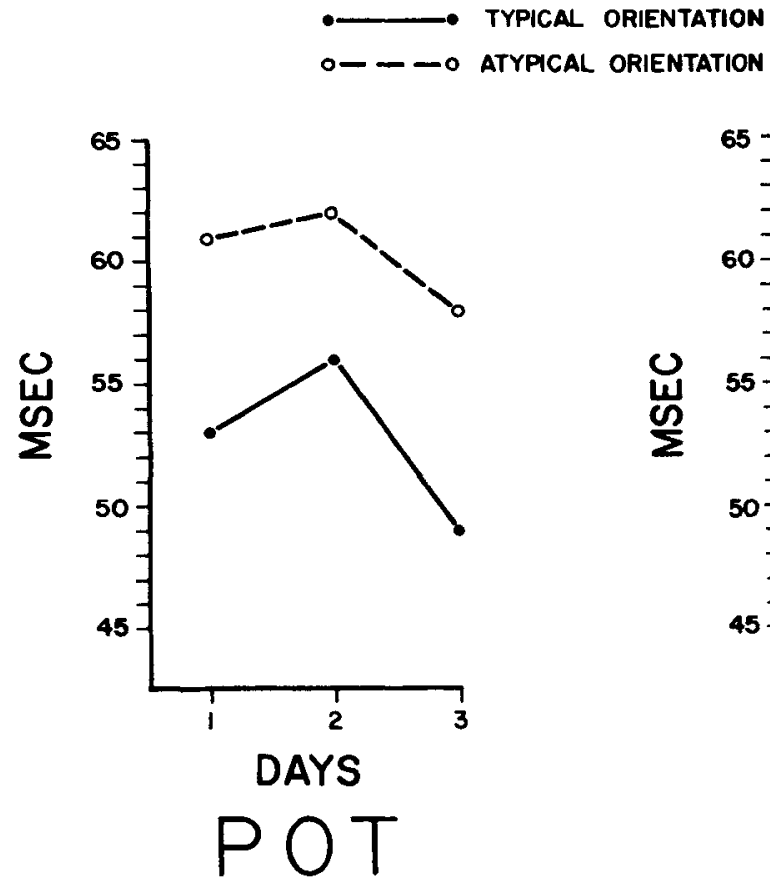
fact that succession threshold is lower for typical orientation and order supports these assumptions and suggests that learning to read English establishes both orientation and order parameters of the analysis operation.

\section{REFERENCES}

BRYDEN, M.P., DICK, A. O. \& MEWHORT, D. J.

K. Tachistoscopic recognition of number sequences. Canadian Journal of Psychology, $1968,22,52-59$.

DICK, A. O., \& MEWHORT, D. J. K. Order of report and processing in tachistoscopic recognition. Perception \& Psychophysics, 1967, 2, 573-576.

HUBEL, D. H., \& WIESEL, T. N. Receptive fields of single neurones in the cat's striate cortex. Joumal of Physiology, 1959, 148, 574-591.

LASHLEY, K. S. The problem of cerebral organization. In H. Klüver (Ed,), Biological symposia Vol. VII. Lancaster, Pa.: Catell, 1942.

LASHLEY, K. S. The problems of serial order in behavior. In L. A. Jeffress (Ed.), Cerebral mechanisms in behavior. New York: Wiley, 1951.

MARG, E., ADAMS, J. E., \& RUTKIN, B. Receptive fields of cells in the human visual cortex. Experientia, 1968, 24, 348-350.

McFARLAND, J. H. Sequential part presentation: A method of studying visual form perception. British Journal of Psychology, 1965a, 56, 439-446.

McFARLAND, J. $H$. The effect of different sequences of part presentation on perception of a form's parts as simultaneous. Proceedings of the 73rd Annual Convention of the American Psychological Association, 1965b, 43-44.

McFARLAND, J. H. Some evidence bearing on operations of "analysis" and "integration" in visual form perception by humans. In $W$. Wathen-Dunn (Ed.), Models for the perception of speech and visual form. Boston: M.I.T. Press,
1967.

\section{NOTES}

1. This work was supported by PHS Grant MH 12449.

2. This is a revised version of a paper presented at the Center for Visual Science. An abstract appears in Record of the Center for Visual Science Third Annual Symposium, Theory of Temporal Factors in Vision and Visual Perception, June 6-8, 1966, Rochester, New York.

3. Address: Department of Psychology, An tioch College, Yellow Springs, Ohio 43710.

4. Since the tachistoscope is the most common instrument available for visual perception studies, these assumptions are dictated by the constraints of the tachistoscope.

5. The concept of integration is used here in the sense of temporal summation.

(Accepted for publication April 28, 1969.) 